\title{
Combination of Interoceptive Exposure Exercise and Aerobic Exercise on Anxiety Severity among College Students
}

\author{
M. Paulraj, R. Ranjani and Simulia Dhinju B
}

\begin{abstract}
Aim: Higher education is a stressful period in student's life due to various reasons like heavy syllabus, exam stress and living away from families for study purpose leads to psychological problem. Anxiety is a common, serious mental health problem. Many studies have conducted on cognitive behavioral therapy, but there is paucity prevails in research field with the combination of Interoceptive exposure exercise (IE), one of the component of cognitive behavioral therapy and aerobic exercises on anxiety among college students. So this study directs to find out the effectiveness of interceptive exposure exercises and aerobic exercise on anxiety subjects in college students. Method: After getting consent from students, 40 subjects were selected and grouped into two groups. Group A- 20 subject receives aerobic exercise and Group B - 20 subjects receives combination of Interoceptive exposure exercises and aerobics. Before and after the intervention Hamilton anxiety scale (HAM-A Scale) was used to assess the anxiety severity of college students. Results: The result was found to be significant between pre and post interventions in both the groups. Between the group analysis shows that there is a statistically extremely significant changes in unpaired ' $\mathrm{t}$ ' test value of group B (experimental group) HAM-A ( $\mathrm{t}=2.82$; $\mathrm{p}<0.05$ ) than the group A (control group). Conclusion: It has been concluded that the Interoceptive Exposure Exercise along with Aerobic exercise showed significant improvement which was noted 6 weeks post intervention.
\end{abstract}

\begin{tabular}{|c|c|}
\hline $\begin{array}{l}\text { M. Paulraj } \\
\text { Associate Professor } \\
\text { Sri Venkateshwaraa College of Physiotherapy } \\
\text { No: 13A, Pondy - Villupuram Main Road, Ariyur, } \\
\text { Puducherry - 605102 (India) } \\
\text { Email: paulphysio@ yahoo.in } \\
\text { R. Ranjani } \\
\text { BPT intern } \\
\text { Sri Venkateshwaraa College of Physiotherapy } \\
\text { No: 13A, Pondy - Villupuram Main Road, Ariyur, } \\
\text { Puducherry - 605102 (India) } \\
\text { Simulia Dhinju B } \\
\text { Assistant Professor } \\
\text { Sri Venkateshwaraa College of Physiotherapy } \\
\text { No: 13A, Pondy - Villupuram Main Road, Ariyur, } \\
\text { Puducherry - 605102 (India) }\end{array}$ & $\begin{array}{l}\begin{array}{l}\text { Key Words: } \begin{array}{c}\text { Anxiety } \\
\text { Interoceptive }\end{array} \text { Exposure } \\
\text { Exercise, } \\
\text { Aerobic Exercise }\end{array} \\
\text { DOI: } 10.18376 / \text { jesp/2019/v15/i2/153521 }\end{array}$ \\
\hline
\end{tabular}

\section{Introduction}

Higher education is a stressful period in student's life that leads to psychological problem (Jayasree $\mathrm{M}$ and Cassedy 2002). Anxiety is a common, serious mental health problem and it is afflicting adolescents and student population to a larger extent. It is a top presenting concern among college students (41.6percent), followed by depression (36.4percent) and others (35.8) (American Psychological Association, 2015). According to World Health Organization (WHO), mental health is considered as an important component of human health (Broman-Folks et al., 


\section{Journal of Exercise Science \& Physiotherapy Vol. 15 No. 2 (July to December) 2019 ISSN: 0973-2020 (Print) $\quad \mathrm{I}_{2}$ OR Impact Factor $=6.502 \quad$ ISSN: 2454-6089 (Online)}

2004). Many studies have reported that under diagnosis of such issues could lead to higher chance of psychiatric disorders resulting in serious impact on their careers and social life. The Hamilton anxiety scale was one of the first rating scales developed to measure the severity of anxiety symptoms and is still widely used today in both clinical and research settings. Interoceptive exposure exercise (IE) is one of the components of cognitive behavioral therapy (Craske and Barlow,2006). This approach includes three primary components: a) Strategies to reduce physiological arousal, b) Interventions to address cognitive misinterpretation of panic-related sensations, c) Exercise to expose the patient to feared stimuli. This intervention is termed as Interoceptive exposure exercise and it reduces anxiety. Aerobic exercise is also one of the effective procedures for reducing anxiety. The neurobiological effects of aerobic exercise are numerous and involve an extensive range of interrelated effects on brain structure, brain function and cognition. The cardiovascular benefit of aerobic exercise significantly decreases blood pressure after 30 minutes of aerobic exercises (Colcombe, et al, 2003). The psychological benefits of the aerobic exercises also reduce depression, stress, anxiety and so-on. Hence the present study evaluated the effect of combination of Interoceptive exposure exercise and aerobic exercise on mild to moderate anxiety subjects.

\section{Materials and Method}

A randomized clinical control trial conducted in Sri Venkateshwaraa college of physiotherapy, Ariyur at Pondicherry, India. (Figure1).After getting consent from subjects, 40 subjects were randomly selected into two groups. A Group A- 20 subjects receives aerobic exercise and Group B - 20 subjects receive combination of Interoceptive exposure exercises and aerobics. Before and after the intervention Hamilton anxiety scale (HAM-A Scale) was used to assess the anxiety severity of college students.

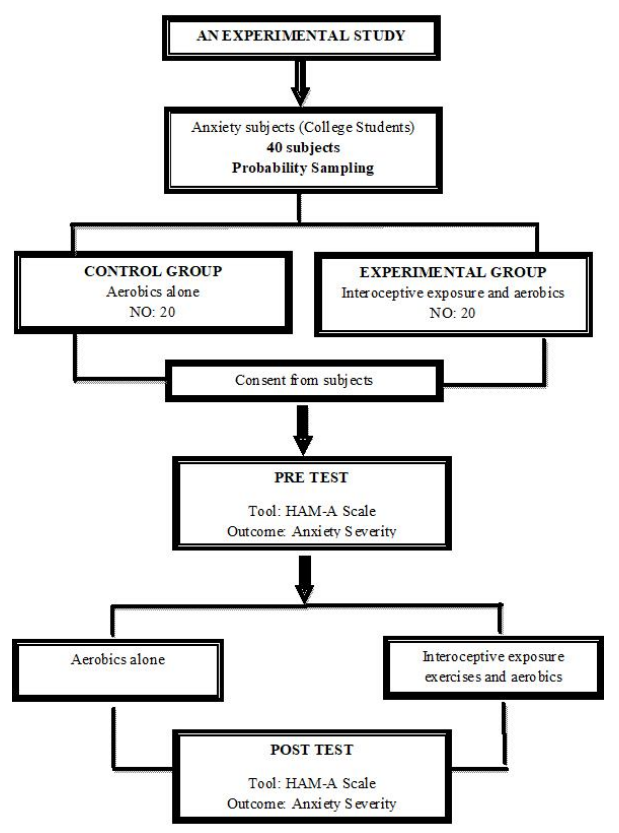

Flow Chart of Study And Participant 


\section{Journal of Exercise Science \& Physiotherapy Vol. 15 No. 2 (July to December) 2019 \\ ISSN: 0973-2020 (Print) I IOR Impact Factor =6.502 ISSN: 2454-6089 (Online)}

\section{Interoceptive Exposure Exercise}

Interoceptive exposure exercise consists of subjects spinning with the prescribed eye glasses on, Stimulus deprivation, hyperventilation ( $1 \mathrm{~min})$, hyperventilation $(5 \mathrm{~min})$, hyperventilation plus spiral staring, strobe light, hyperventilation plus strobe light. All 7 exercises were took place in a $2.44 * 3.05 \mathrm{~m}$ windowless room containing two chairs, a desk and the materials described here. Before each exercise, participants were given the corresponding instructions, asked not to suppress or avoid any sensations that might occur and reminded of the ratings to be made following each exercise. For all exercises, the experimenter stood quietly in the corner of the room (Abramowitz et al, 2010).

Spinning with Prescribed Eyeglass: Each participant was asked to spin with the prescribed eyeglasses on (Figure1). The experimenter instructed participants to spin for 30 seconds and rest in place for 30 seconds.
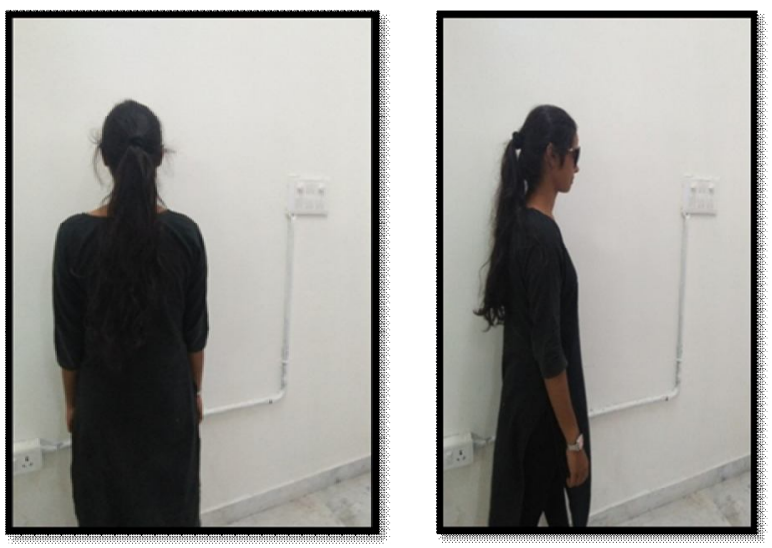

Figure 1. Spinning with prescription eyeglass

Stimulus Deprivation: Participants stood in the center of a dark room while wearing a blindfold and noise-blocking head phones for 3 minutes and eyes should be closed (Figure 2).

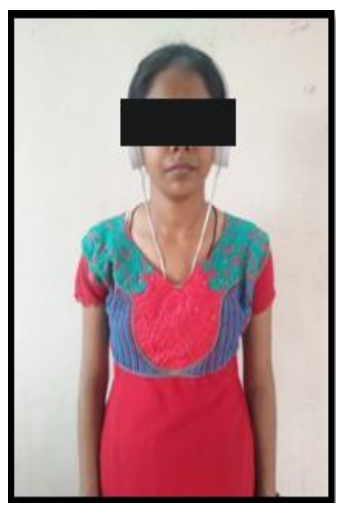

Figure 2.Stimulus deprivation 


\section{Journal of Exercise Science \& Physiotherapy Vol. 15 No. 2 (July to December) 2019 \\ ISSN: 0973-2020 (Print) $\quad \mathrm{I}_{2} \mathrm{OR}$ Impact Factor $=6.502 \quad$ ISSN: 2454-6089 (Online)}

Hyperventilation (1Minute): Participants stood in the experiment room and hyperventilated for 1 minute (Figure 3). The participants were asked to breathe in as deeply as they could and then breathe out completely at a rate of 45 breaths each minute in accordance with an audiotape repeating the words in and out at the correct pace.

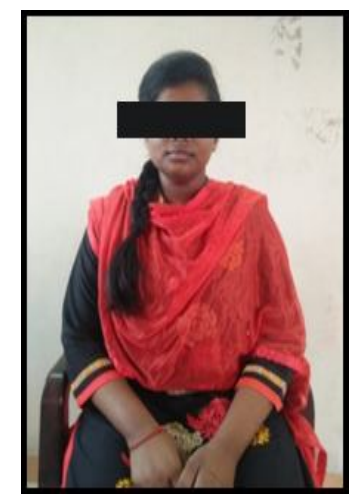

Figure 3. Hyperventilation for 1 minute

Hyperventilation (5 Minute): This exercise was the same as the hyperventilation (1minute) exercise except subjects were asked to hyperventilate for 5 minute, during which time they were given five normal breathing breaks. "The normal breathing breaks" lasted for 15 seconds and began at the 45 second mark of each minute (Figure 4). i.e., 45 seconds, 1minute 45 seconds and so on.

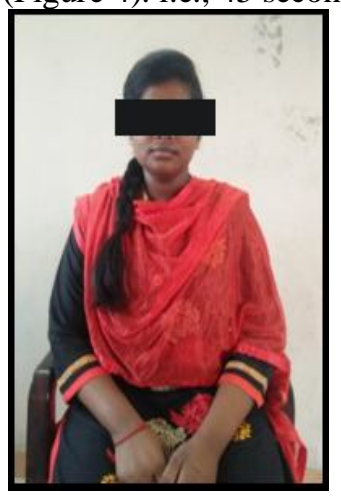

Figure 4: Hyperventilation for 5 minute

Hyperventilation Plus Spiral Staring: Anxiety subjects were seated at a desk and instructed to stare at the moving spiral, following the same spiral staring procedures detailed previously, for 3 minutes. While staring at the spiral, participants hyperventilated following the same hyperventilation procedure, described previously at a speed of 45 breathe each minute (Figure 5). Participants were given three times fifteen seconds normal breathing breaks, during which they instructed to continue staring at the center of the moving spiral. 


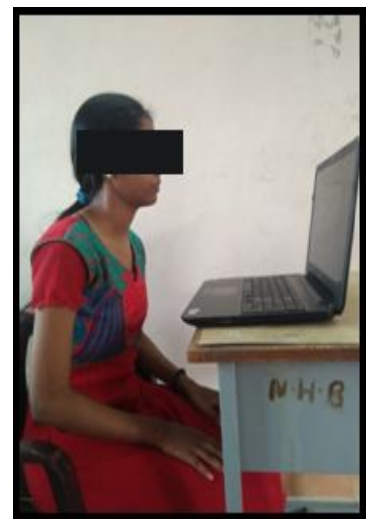

Figure 5: Hyperventilation plus Spiral

Strobe Light: The subjects were asked to stand in the middle of the dark experiment room with an inexpensive strobe light placed on the seat $1 \mathrm{~m}$ behind them. During this exercise, subjects were instructed to stand and stare at the centre of their shadow on the wall before them for 3 minutes (Figure 6). The strobe light speed was adjusted to $75 \%$ of full speed. The experimenter stood outside the participant field of vision.
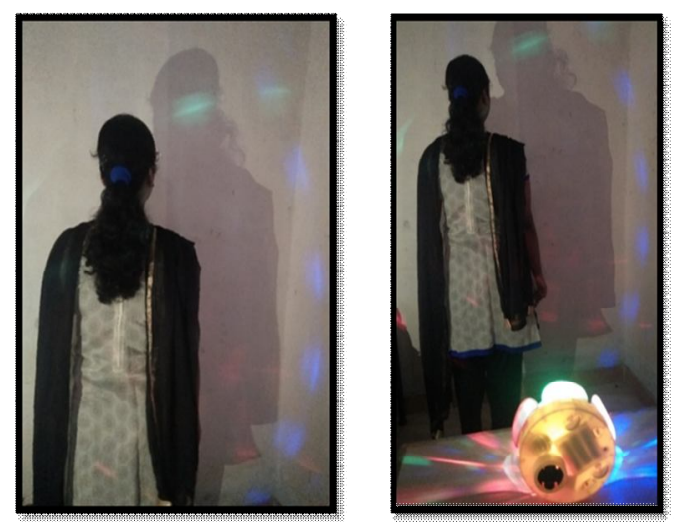

Figure 6: Strobe light

Hyperventilation Plus Strobe Light: The participant stood in the dark room with a strobe light, following the same procedure as detailed previously while hyperventilating for the period of 3 minutes, following the same hyperventilation procedures previously described (Figure 7). Participants were given three 15 secondsnormal breathing breaks, during which they were asked to continue starring at window (Abramowitz et al, 2010). 


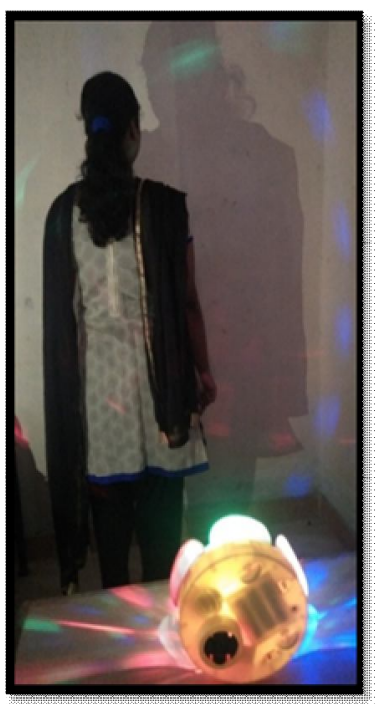

Figure7: Hyperventilation Plus strobe light

\section{Aerobic Exercise:}

The training program took place during 8 consecutive weeks in a college. It was held three times a week for 45 minutes' period of time. Sessions included warm-up; progressive aerobic, muscular; motor skills exercise and cool down. Various physical activities were used in order to maintain motivation of the participants and the adherence in the program (Figure 8 and 9). Aerobic dance, step up exercise and tag and ball games were examples of aerobic activities used in the training sessions (Brett $\mathrm{J}$ et al 2013.).

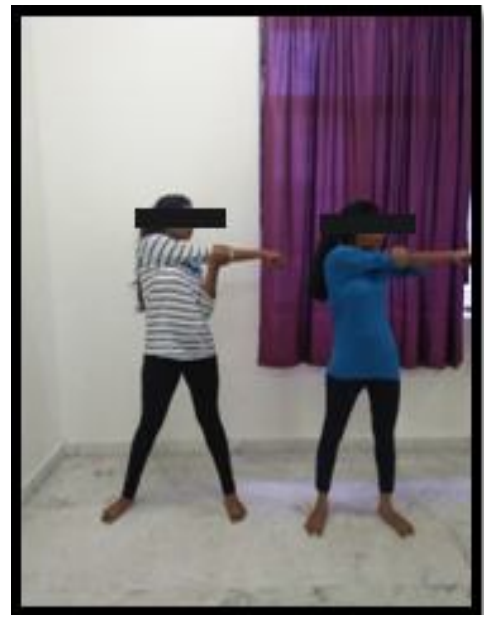

Figure 8: Warm-up exercise

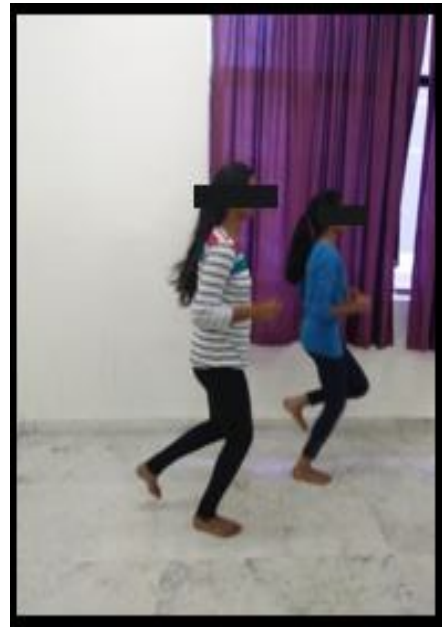

Figure 9: Jogging 


\section{Results}

Table 1 shows that the p value of HAM-A scale of control group is above 0.05 , considered very significant. The t value of HAM-A scale for control group is 9.95 with 19 degree of freedom.

Table 1: Within group analysis of HAM-A scale in control group

\begin{tabular}{|l|l|l|l|}
\hline CONTROL GROUP & MEAN \pm SD & t-VALUE & p-VALUE \\
\hline PRE TEST & $20.1 \pm 2.27$ & 9.95 & $<0.001$ \\
\cline { 1 - 2 } & & & \\
\hline
\end{tabular}

Table 2 shows that the $\mathrm{p}$ value of HAM-A scale of experimental group is $<0.001$, considered very significant. The $\mathrm{t}$ value of HAM-A scale for experimental group is 11.57 with 19 degree of freedom.

Table 2: Within group analysis of HAM-A scale in experimental group

\begin{tabular}{|l|l|l|l|}
\hline EXPERMENTAL GROUP & MEAN $\mathbf{S D}$ & t-VALUE & p-VALUE \\
\cline { 1 - 2 } PRE TEST & $21.1 \pm 2.43$ & 11.9 & $<0.001$ \\
\cline { 1 - 2 } POST TEST & $12 \pm 2.29$ & & \\
\hline
\end{tabular}

Table 3 shows that the $\mathrm{p}$ value of HAM-A scale is 0.001 considered very significant. The $t$ value of HAM-A scale is 2.82 with 38 degree of freedom. The above paired ' $t$ ' test data result was found to be significant between pre and post interventions in both groups. Between the group analysis shows a statistically extremely significant changes in unpaired ' $t$ ' test value of group B (experimental group) HAM-A $(\mathrm{t}=2.82 ; \mathrm{p}<0.05)$ than the group A (control group).

Table 3: Between group analysis of HAM-A scale in both groups

\begin{tabular}{|l|l|l|l|l|}
\hline GROUPS & MEAN & SD & t-VALUE & p-VALUE \\
\cline { 1 - 3 } Control group & 6.3 & 2.8 & 2.82 & $<0.001$ \\
\cline { 1 - 3 } Experimental group & 9.1 & 3.4 & & \\
\hline
\end{tabular}

\section{Discussion}

This study proved that improvement was seen in both the treatment groups to reduce anxiety severity in college students. After the statistical analysis it was found that Interoceptive exposure exercise along with aerobic exercise shows significant improvement, which was noted 6 weeks of post intervention in all the clinical parameters. Our results using bolster support for Interoceptive exposure exercise found to be an effective method in reducing anxiety for a due course of time. It may have a greater expectation for improvement in mental status of college students (Brett Deacon et al, 2013). Therefore, the current study duration of 6-week program definitely improve the mental status and reduce the anxiety severity. The psychological benefit of aerobic exercise is to reduce 


\section{Journal of Exercise Science \& Physiotherapy Vol. 15 No. 2 (July to December) 2019 ISSN: 0973-2020 (Print) $\quad \mathrm{I}_{2} \mathrm{OR}$ Impact Factor $=6.502 \quad$ ISSN: 2454-6089 (Online)}

anxiety. Sexton et al, (1989), who found comparable reduction in anxiety for participants who exercised by jogging and those who participated light walking. In addition the aerobic exercise used in this study was walking, jogging and running. In this study there by aerobic exercises could have reduced the anxiety (Watt M, 2006). The pre and post value of Anxiety severity were assessed using HAM-A scale. From the statistical analysis, experimental group shows (paired 't' test) in the outcome measure HAM-A scale shows 11.9 whereas in the group A of HAM-A scale is 9.95. In between group analysis (the unpaired ' $t$ ' test) shows 2.82 . Based on this result the data accepts the alternate hypothesis and reject the null hypothesis. Hence, the experimental group treated with Interoceptive exposure exercise was showed significant improvement in anxiety severity, thereby improving the mental status like attention, concentration, memory and so-on.

\section{Conclusion}

From the above results and the discussion, it was concluded that the Interoceptive Exposure Exercise along with Aerobic exercise showed significant improvement in anxiety severity among college students which was assessed 6 weeks post intervention. Interoceptive exposure exercise task like hyperventilation, spinning with prescription of hyperventilation, stimulus deprivation and hyperventilation with strobe light have significant effect on the fears of physical sensations experienced by college students. Thereby improving the mental status likes attention, concentration, memory and so-on.

Acknowledgements: I would like to acknowledge Professor Dr. A.Pahinian PhD, MPT, MBA, Principal, Sri Venkateshwaraa College of Physiotherapy, Puducherry and entire faculty members who helped me to complete this work with adequate instruction.

\section{References}

Abramowitz, J.s., Deacon, B.J., Whiteside, S.P 2010. Exposure therapy for anxiety: principles and practice, New York; Guilford press.

American Psychological Association. 2015.

Brett Deacon et al 2013. Maximizing the efficacy of Interoceptive exposure by optimizing inhibitory learning: A randomized controlled trial. Behavior Research and Therapy 51, 588-596.

Brett J. Deacon, PhD., James J. Lickel, et al 2013. Cognitive Reappraisal and Diaphragmatic Breathing Augment Interoceptive Exposure for Anxiety Sensitivity? Journal of Cognitive Psychotherapy: An International Quarterly Volume 26, Number 3.

Broman-Folks, et al 2004. Effects of aerobic exercise on anxiety sensitivity. Behavior Research and Therapy, 42(2): $125-136$.

Colcombe S. J., et al. 2003. Aerobic fitness reduces brain tissue losing aging humans. A. Biol. Sci. Med. Sci. 58:176-180.

Craske MG., Barlow DH.2006. Mastery of Your Anxiety and Worry. 2nd ed. New York, NY: Oxford University Press.

Jayasree M. Cassedy 2002. Cognitive Test Anxiety and Academic Performance Contemporary Educational Psychology 27, 270-295.

Sexton, Maere Dahl, H Sexton, A Maere and N.H Dahl.1989. Exercise intensity and reduction in neurotic symptoms-a controlled follow-up study. Acta Psychiatricia Scandinavia, 80, pp. 231-235.

Watt, M., Stewart, S., Birch, C., \& Bernier, D. 2006. Brief CBT for high anxiety sensitivity decreases drinking problem, relief alcohol expectancies, and conformity drinking motives: Evidence from a randomized, control trial. Journal of Mental Health, 15, 683-695.

Conflict of Interest: None declared 